\title{
Comparison of two model approaches in the Zambezi river basin with regard to model reliability and identifiability
}

\author{
H. C. Winsemius ${ }^{1}$, H. H. G. Savenije ${ }^{1}$, A. M. J. Gerrits ${ }^{1}$, E. A. Zapreeva ${ }^{2}$, and R. Klees ${ }^{2}$ \\ ${ }^{1}$ Water Resources Section, Faculty of Civil Engineering and Applied Geosciences, Delft University of Technology, \\ Stevinweg 1, P.O. Box 5048, 2600 GA Delft, The Netherlands \\ ${ }^{2}$ Institute of Earth Observation and Space Systems (DEOS), Physical and Space Geodesy group, Delft University of \\ Technology, Kluyverweg 1, P.O. Box 50582600 GB, Delft, The Netherlands
}

Received: 16 September 2005 - Published in Hydrol. Earth Syst. Sci. Discuss.: 7 December 2005

Revised: 21 February 2006 - Accepted: 13 March 2006 - Published: 11 May 2006

\begin{abstract}
Variations of water stocks in the upper Zambezi river basin have been determined by 2 different hydrological modelling approaches. The purpose was to provide preliminary terrestrial storage estimates in the upper Zambezi, which will be compared with estimates derived from the Gravity Recovery And Climate Experiment (GRACE) in a future study. The first modelling approach is GIS-based, distributed and conceptual (STREAM). The second approach uses Lumped Elementary Watersheds identified and modelled conceptually (LEW). The STREAM model structure has been assessed using GLUE (Generalized Likelihood Uncertainty Estimation) a posteriori to determine parameter identifiability. The LEW approach could, in addition, be tested for model structure, because computational efforts of LEW are low.

Both models are threshold models, where the non-linear behaviour of the Zambezi river basin is explained by a combination of thresholds and linear reservoirs.

The models were forced by time series of gauged and interpolated rainfall. Where available, runoff station data was used to calibrate the models. Ungauged watersheds were generally given the same parameter sets as their neighbouring calibrated watersheds.

It appeared that the LEW model structure could be improved by applying GLUE iteratively. Eventually, it led to better identifiability of parameters and consequently a better model structure than the STREAM model. Hence, the final model structure obtained better represents the true hydrology.

After calibration, both models show a comparable efficiency in representing discharge. However the LEW model shows a far greater storage amplitude than the STREAM model. This emphasizes the storage uncertainty related to
\end{abstract}

Correspondence to: $\mathrm{H}$. C. Winsemius

(h.c.winsemius@tudelft.nl) hydrological modelling in data-scarce environments such as the Zambezi river basin. It underlines the need and potential for independent observations of terrestrial storage to enhance our understanding and modelling capacity of the hydrological processes. GRACE could provide orthogonal information that can help to constrain and further enhance our models. In the near future, other remotely sensed data sources will be used to force modelling efforts of the Zambezi (e.g. satellite rainfall estimates) and to identify individual storage components in the GRACE observations (e.g. altimeter lake levels and microwave soil moisture). Ultimately, this will create possibilities for state updating of regional hydrological models using GRACE.

\section{Introduction}

Certain hydrological variables such as water storage in the unsaturated and saturated zone and evaporation are difficult to observe directly, particularly at larger spatial scales, such as: pixels, sub-catchments and river basins. Therefore it is unavoidable that parameters related to these variables are determined through calibration on often limited discharge timeseries at the outlet of a catchment. Especially in distributed models, this usually results in "equifinality", where a large number of possible parameter sets perform equally well, but introduce high parameter uncertainty (Beven and Binley, 1992; Beven and Freer, 2001; Savenije, 2001). In the process of identifying relevant hydrological processes and parameters, it often appears that one parameter can easily "correct" for another poorly chosen parameter value, whereas physically these parameters are not correlated. Another problem with discharge time series is that in many tropical regions, the discharge is often a relatively small flux compared to the

Published by Copernicus GmbH on behalf of the European Geosciences Union. 


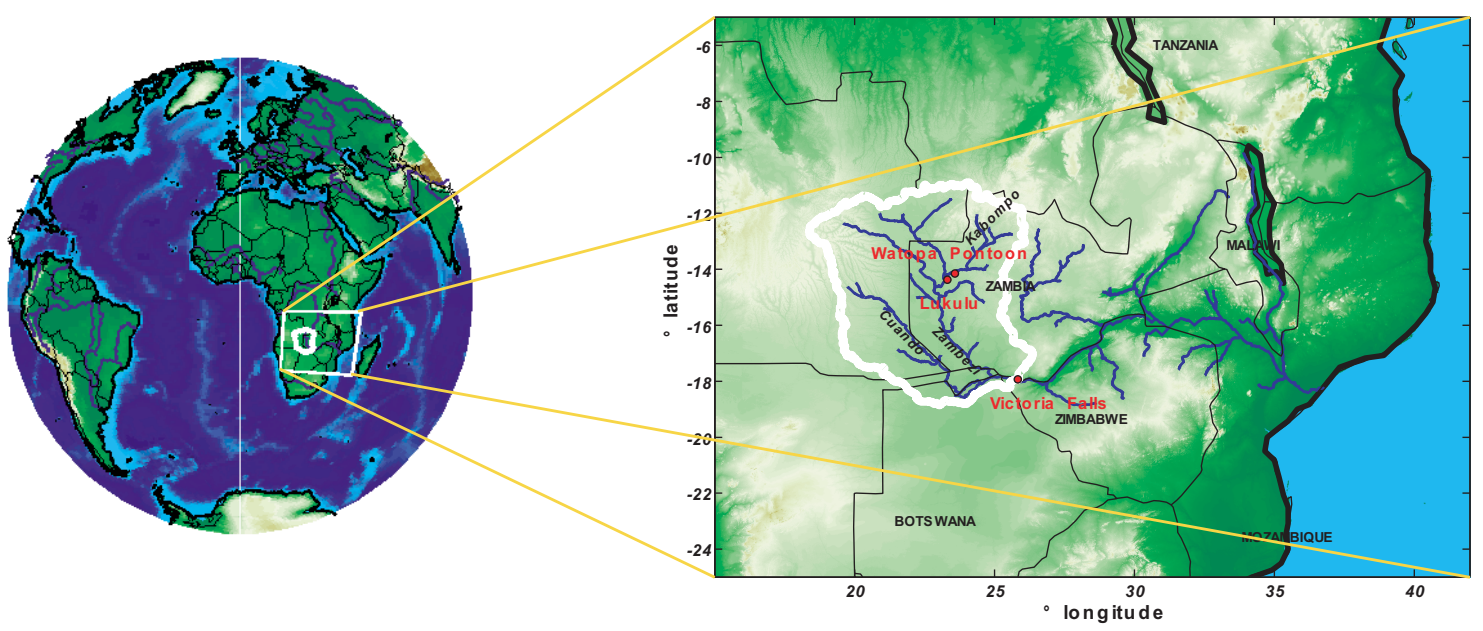

Fig. 1. Topography and stream flow network of the upper Zambezi and its surroundings.

rainfall. As a result, river discharge provides relatively limited information on internal hydrological processes.

To prevent equifinality in calibration, the number of calibration parameters should be limited. This forces a modeller to either use a parsimonious model (using the smallest number of calibration parameters) or to try and identify parameters as much as possible from available data. Using only outlet stream flow data restricts this possibility seriously, especially when a highly distributed form of modelling is concerned. Even a series of nested stream gauges does often not allow for a detailed spatial identifiability of parameters. More spatially distributed data on e.g. groundwater levels, soil moisture or evaporation could enable further constraining of parameters.

It becomes more and more evident that remotely sensed data offer a treasure of spatially distributed information, which can be used to identify and parameterize relevant hydrological processes at smaller spatial scales. Evaporation for example, can have a high spatial variability and can be monitored indirectly through satellite imagery. Mohamed et al. $(2004,2005)$ for instance prepared actual evaporation maps and moisture storage maps based on the Surface Energy Balance Algorithm for Land (SEBAL) (Bastiaanssen et al., 1998). These were used to enhance the understanding of land-atmosphere interactions in and around the upper Nile swamps. Evaporation from these swamps turned out to be substantially less than was estimated earlier (Sutcliffe and Parks, 1999), which could be explained by larger areas of swamps, not being permanently saturated throughout the year.

In addition soil moisture in the top few centimeters can be monitored through remote sensing: a study by Franks et al. (1998) shows that the number of behavioural TOPMODEL parameterizations for a small catchment $\left(12(\mathrm{~km})^{2}\right)$, conditioned on discharge alone, can be further constrained by incorporating estimates of saturated areas derived from ERS-1
Synthetic Aperture Radar (SAR) images combined with the TOPMODEL topographic index. In a more recent study (Scipal et al., 2005), macro scale soil moisture data from the ERS scatterometer were averaged over basin areas upstream of gauging points and correlated with measured stream flow in the Zambezi river. The high correlations between soil moisture and stream flow that were found, indicate that also the use of macro-scale remotely sensed soil moisture data may constrain parameterizations of hydrological models.

Until recently, there was no way to monitor the true water stock directly. Top layer soil moisture does not say anything about the total water availability in the unsaturated zone. It merely provides some indication of the latter, which should be translated into an applicable value, directly related to the modelled unsaturated zone storage. Recently, a new venue of hydrological state observations became available: the Gravity Recovery And Climate Experiment (GRACE) offers not yet fully explored possibilities to monitor total terrestrial storage variations (unsaturated zone, saturated zone, lakes, ponds, rivers, snow, etc.) at river basin level. With GRACE we have a tool, which does not merely provide an indication of stocks, but a true stock variation encompassed in the total mass redistribution signal. GRACE provides in this sense "orthogonal" information, meaning that it gives independent information on the dynamics of a certain variable within the model (in this case the storage), without being correlated to other sources of information, used to infer parameterizations or model structures. It will help us gain insight about the validity of our chosen parameters, specifically those directly related to the storage, and model structure, meaning that it can be used to refine our models and constrain the number of parameterizations. A better representation of the stocks should lead to more reliable simulation of the associated fluxes, which will result in reduction of model uncertainties and improvement of predictions of floods and droughts. 

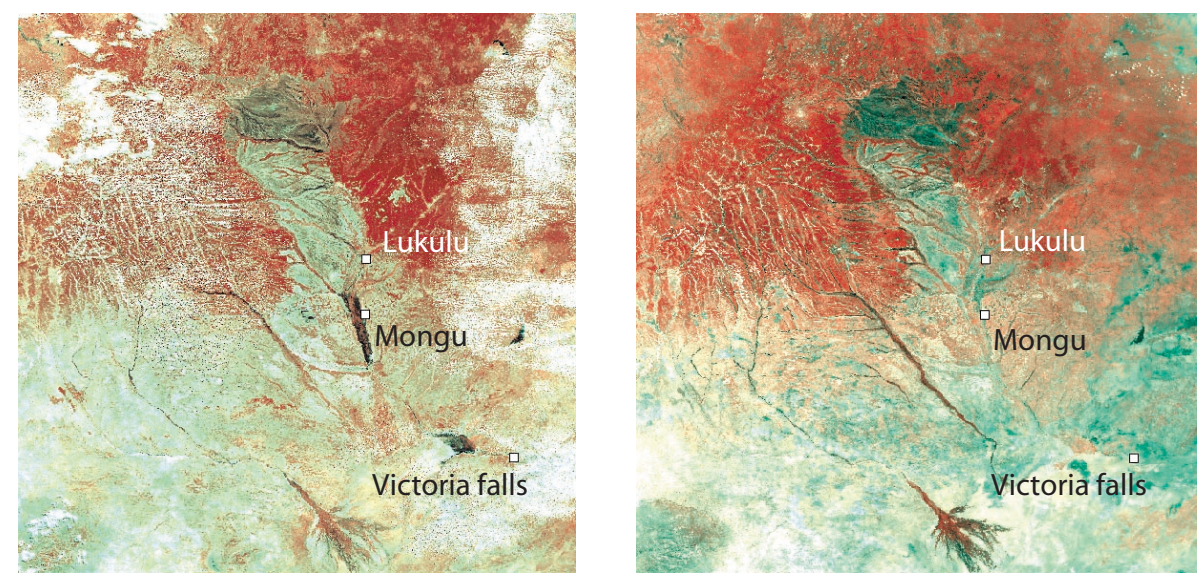

Fig. 2. MODIS $250 \mathrm{~m}$ channel 2 images of the study area. Left: the beginning of the dry season. Right: the end of the dry season.

This paper addresses the need for internal stock observations, by showing the differences that occur when different approaches are followed while modelling a large river basin. It turned out that the Generalized Likelihood Uncertainty Estimation framework (GLUE) (Beven and Binley, 1992) can be used not only to constrain possible parameterizations, but also to constrain the choice between possible model structures if computational efforts are not too high. The goal of the modelling exercise is to eventually compare modelled storage with GRACE observations in a future study. By comparing results between two different conceptual models of the upper Zambezi basin, the possible application of these observations is underlined. The behaviour of both models is analyzed with emphasis on runoff and storage.

\section{The upper Zambezi river basin}

\subsection{Hydrology}

The upper Zambezi (Fig. 1) is defined as the area upstream of Victoria Falls (ca. $500000(\mathrm{~km})^{2}$ ). The river springs from the northern areas of Zambia, flows to the west into Angola and shortly afterward bends southwards entering the Western Province in Zambia. The surroundings of the river are vast and shallow floodplains and are governed by very low gradients and high evaporation. This area is generally dry during the dry season and floods extensively during the wet season as can be observed in satellite imagery (Fig. 2).

In this floodplain area, a number of tributaries such as the Kabompo, Luena and Luanginga join the Zambezi. The river converges at the gauging station of Lukulu. Downstream of Lukulu, the river flows into the Barotse plain: a shallow wide floodplain area consisting of several tens of meters deep Kalahari sands, an enormous phreatic groundwater reservoir. More downstream, the river bends to the west and passes Victoria Falls where the river drops into a narrow gorge. Elevation maps suggest that the Okavango and Cuando rivers enter

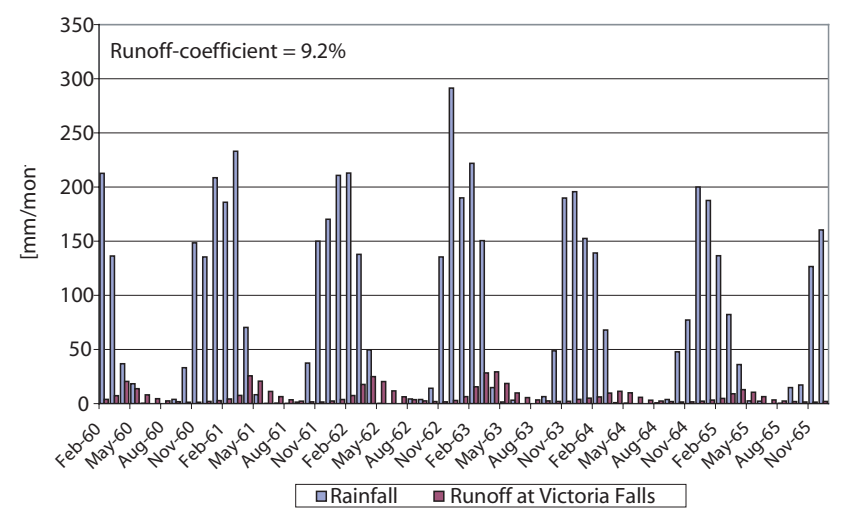

Fig. 3. Five consecutive years of precipitation and runoff numbers for the upper Zambezi.

the Zambezi east of Victoria Falls through the Caprivi Strip. However, flow through the Caprivi Strip only occurs during extremely wet years. Downstream from Victoria Falls, 2 major man-made reservoirs are located: lake Kariba (completed in 1955), shared by Zambia and Zimbabwe, and Cahora Bassa (completed in 1974) in Mozambique.

The slopes in the basin are on average quite low, hence many marshlands and groundwater dominated wetlands can be found, especially in the direct neighbourhood of the river and in the downstream areas of tributaries (Bastiaansen, 1995). A large amount of water can be retained in these wetlands, where it is either evaporated or stored over longer periods. The high evaporation potential is the largest reason for the low runoff coefficients found throughout the upper Zambezi (see Fig. 3). A schematic overview of the hydrological processes governing the upper Zambezi tributaries is shown in Fig. 4. The hydrology can roughly be sub-divided in 3 classes: uplands, wetlands and floodplains. Rainfall is partitioned into direct evaporation from the surface (interception) and infiltration to the unsaturated zone, where it partly 


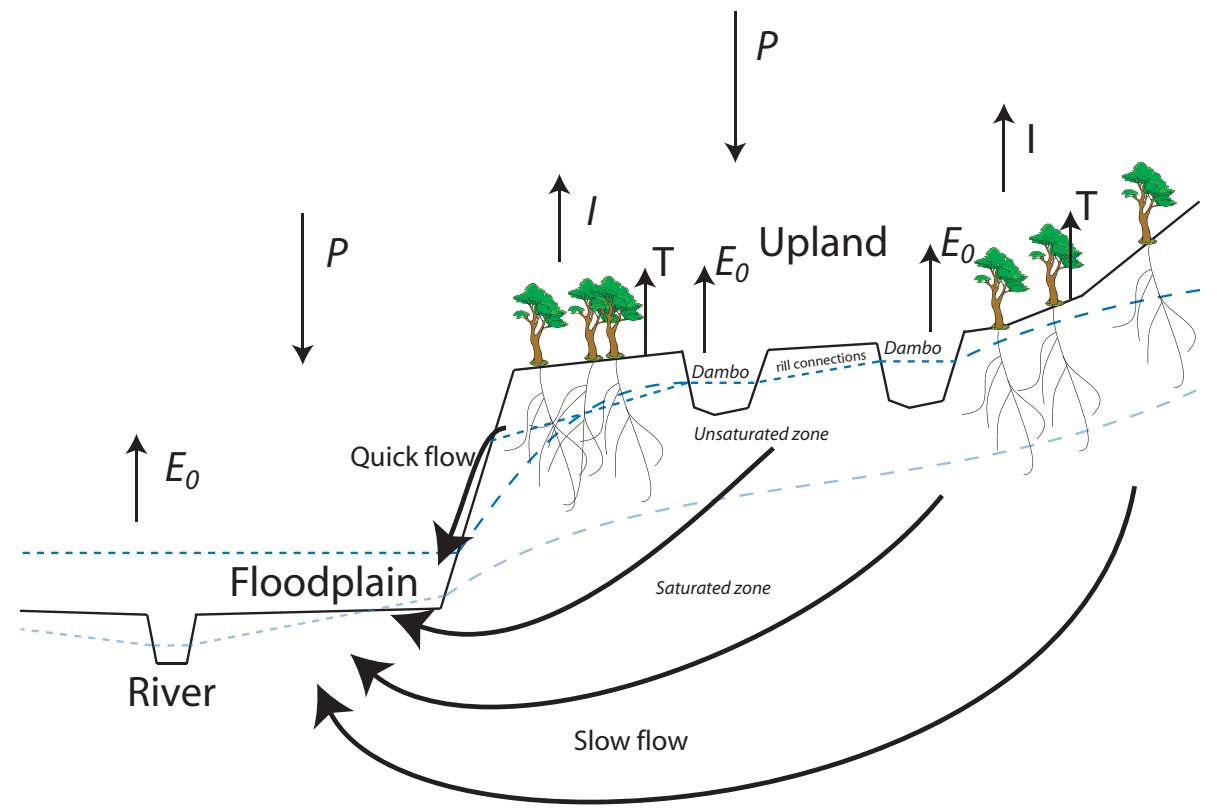

Fig. 4. Overview of the governing hydrological processes in the upper Zambezi.

transpires and partly percolates. Surface runoff only occurs due to saturation of the soil in the lower lying areas and wetlands (dambos). In the wet season, the groundwater levels rise and the dambos flood. Quick response flows are generated by threshold behaviour: when the dambo levels exceed a threshold level, a drainage network starts to develop. Slow flow occurs from the deep groundwater. In the floodplains, low slopes result in low channel capacities. Therefore runoff generated from the dambos can spill and re-infiltrate in the Kalahari sands of the downstream floodplains.

No major changes in the hydrology of the upper Zambezi have taken place in the past century. It is therefore assumed that the river's hydrological behaviour is stationary.

\subsection{Climate}

The climate of the Zambezi river basin is governed by the movement of the Inter-Tropical Convergence Zone (ITCZ). It causes one rainy season per year from December until April, which is responsible for the strongly seasonal character of the discharge in the Zambezi. In general, precipitation increases northward. Yearly rainfall numbers vary from about $500 \mathrm{~mm} \mathrm{yr}^{-1}$ in the south to up to $1300 \mathrm{~mm} \mathrm{yr}^{-1}$ in the north according to the global climatology dataset from the Climate Research Unit (CRU) (New et al., 2002).

In the uplands, evaporation is moisture constrained. In the wetlands however, it depends on the season what constrains evaporation. During the wet season, many of the wetlands are fully saturated and even flooded. Then, the reference evaporation (in this study used as a surrogate for potential evaporation) limits the amount of evaporation in these areas.

\section{Data sources}

African data sources are generally limited. The length of rainfall records often depends on the political situation. Angola for example has been struck by war since 1975 up to recent periods, which means that only records from the colonial period are available and even those are sometimes difficult to obtain. Therefore a time series of the 1960s was used to calibrate the water balance models. The most complete dataset of gauged time series was found at the Global Historical Climate Network (GHCN) V. 2. It can be downloaded freely from the SAFARI 2000 project website (http: //www.daac.ornl.gov/S2K/safari.html). A quite good coverage in the upper Zambezi was found in the period 19601972. The coverage becomes worse in the early seventies, especially over Angola, probably because of the struggle against Portuguese colonialism. The departure of the Portuguese and the start of the Angolan civil war put an end to gauging missions, which means that a large part of the Zambezi upstream of Lukulu remained ungauged in this period. Spatial estimates of monthly rainfall were determined using the weighted inverse distance method.

Unfortunately, some of the available discharge time series did not cover the same period as the rainfall data. Thus more recent rainfall records were needed. It was chosen to use the second version of the Climate Research Unit's (CRU) monthly grids (New et al., 2002). The grids $\left(0.5 \times 0.5(\mathrm{~km})^{2}\right)$ are based on as much rainfall stations as could be found e.g. from the Global Telecommunication Systems (GTS). It has the advantage that it avoids the struggle for finding rainfall records for individual stations, that it provides a long time 


\section{Precipitation \\ Source}

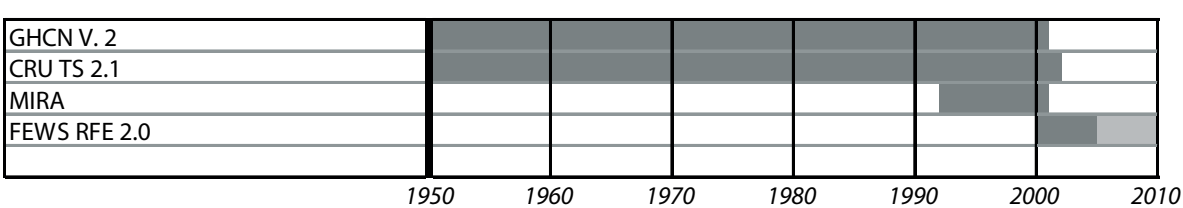

Discharge

Location (river)

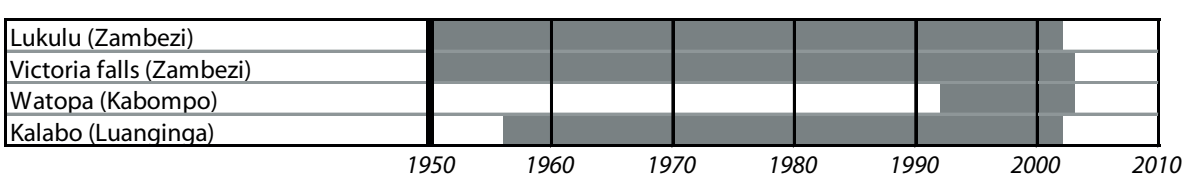

Available time series

Available time series

Fig. 5. Temporal coverage of precipitation and discharge data.

series and even gives a value when the rain station network is very sparse. The disadvantage is that rainfall estimates based on a very small number of rain gauges are unreliable. Therefore, this dataset was used to model the general behaviour of a watershed but only marginally to mimic the exact shape of the hydrograph.

Two more sources of rainfall data were considered to enable running the model during the GRACE time series: the Famine Early Warning System (FEWS) based on METEOSAT 5 and GTS data providing a 10-daily product with $0.1^{\circ}$ resolution (Herman et al., 1997); and the Microwave Infra-Red Algorithm (MIRA) combining satellite passive microwave and infrared data, providing a daily $0.1^{\circ}$ product (Todd et al., 2001). FEWS data can be obtained operationally from http://www.cpc.ncep.noaa.gov/products/fews/. The MIRA time series from 1993 until 2001 is available on http://daac.ornl.gov/.

These rainfall estimates were aggregated to monthly amounts and compared to in situ rainfall records. MIRA overestimates rainfall quite often (up to 50\%) and is also likely to produce some rainfall during completely dry months. This was also concluded by Hughes et al. (2005) ${ }^{1}$ for the neighbouring Okavango river basin. FEWS shows less bias and, unlike MIRA, is still operational. Therefore FEWS will be used in future studies on GRACE and the Zambezi to force the models.

To obtain potential evaporation amounts, PenmanMonteith was applied on reanalysis data of NCEP/NCAR. It is assumed that it provides a coarse estimation, but this is expected to be appropriate because soil moisture is in most places the limiting factor for evaporation, except during the wet season in the flooded wetlands.

Discharge data are available for a small number of gauging stations. Only two are available in the Zambezi river itself at

\footnotetext{
${ }^{1}$ Hughes, D. A., Andersson, L., Wilk, J., and Savenije, H. H. G.: Regional calibration of the Pitman model for the Okavango River, J. Hydrol., submitted, 2005.
}

Lukulu and Victoria Falls. Additionally, two short time series are available in the Kabompo and Luanginga tributaries.

Plots of the time series temporal coverage are given in Fig. 5. Elevation and flow direction have been derived from the USGS HYDRO1k database.

\section{Model development}

Two different model structures were developed, at monthly scale, to represent the hydrology of the upper Zambezi. The use of monthly time steps is justified by the fact that the time scales of the processes in the upper Zambezi are generally very large. Although the presented models have very different characteristics, they both can reach an acceptable level of accuracy in estimating the overall discharge. In this section, we describe the approach followed to construct the models. For both models, the GLUE framework (Beven and Binley, 1992) was used as a means to assess parameter identifiability. It is assumed that a model structure that a posteriori produces well identifiable calibration parameters, is more reliable than one that does not.

\subsection{Spatial Tools for River basin Environmental Analysis and Management (STREAM)}

STREAM (Aerts et al., 1999) is a GIS-based tool to model spatial water balances for environmental studies. GIS-maps are combined using a dynamic script to describe the hydrological processes. For each individual grid cell, in each timestep a water balance is computed. River flow is generated by accumulating surface runoff in the local drainage direction, which is computed from a Digital Elevation Model (DEM). There is no routing of the surface runoff. It is removed from the model within the same time step as it is generated. When time steps are large in relation to the size of the catchment, this is usually an acceptable assumption. The STREAM model is well capable of including spatially 


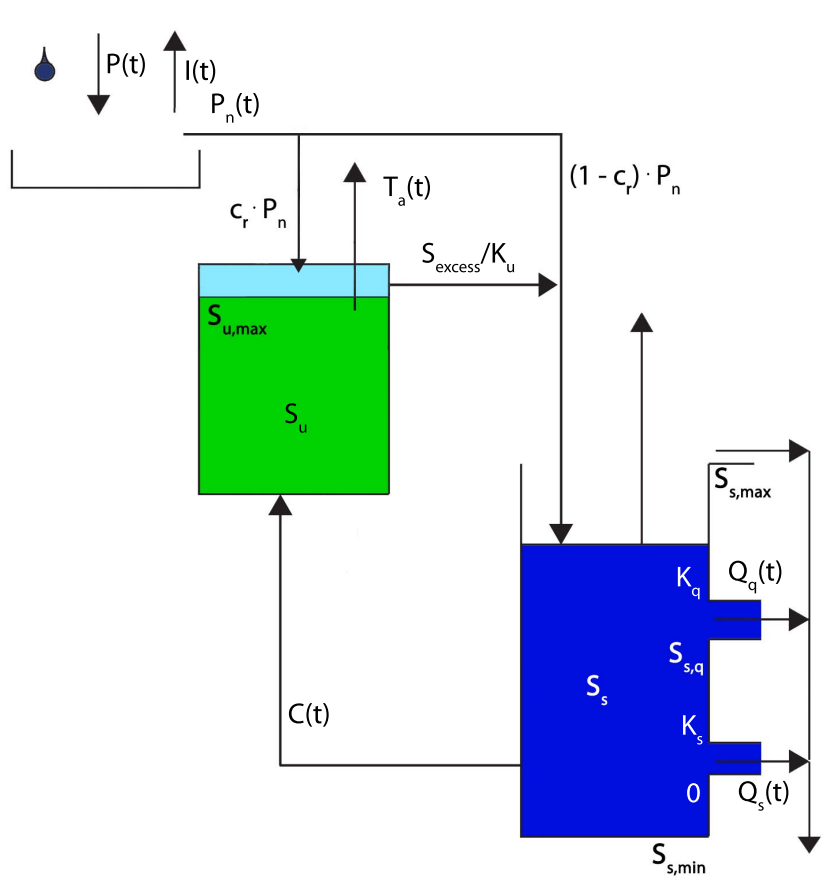

Fig. 6. STREAM conceptual model structure.

variable information in the model. As non-linearities in the Zambezi are a result of threshold exceedances, it is interesting to use STREAM in combination with spatially distributed rainfall sources as this may cause local exceedance of thresholds more often than in a lumped approach.

A STREAM script for the upper Zambezi was developed by Gerrits (2005) (see Fig. 6). The model resolution was chosen to be $3 \times 3(\mathrm{~km})^{2}$ to prevent excessive computation time. The USGS HYDRO1k Digital Elevation Model for Africa was therefore upscaled to $3 \times 3(\mathrm{~km})^{2}$. A local drainage direction map was derived from it. Because of the large residence times in the basin, outputs of the STREAM model were attenuated using a river routing model based on the Muskingum equations.

The model structure consists of two reservoirs: the unsaturated and saturated zone. Net precipitation is calculated by subtracting a fast evaporation threshold, $D\left[\mathrm{~mm} \mathrm{month}^{-1}\right]$ as suggested by Savenije (1997) and Savenije (2004). The fast evaporation consists of interception (evaporation within the same day the rainfall took place, in this study modelled as a monthly threshold) and transpiration from shallow-routing vegetation that transpires within the monthly time step. For convenience this 'fast' evaporation is called interception:

$I=\min \left(P, D, E_{p}\right)$

and

$P_{n}=P-I$

Where
$I=$ Interception $\left[\mathrm{mm} \mathrm{month}{ }^{-1}\right]$

$P \quad=$ Precipitation $\left[\mathrm{mm} \mathrm{month}{ }^{-1}\right]$

$E_{p} \quad=$ Potential evaporation [mm month $\left.{ }^{-1}\right]$

$P_{n} \quad=$ Net precipitation $\left[\mathrm{mm} \mathrm{month}{ }^{-1}\right]$

$D \quad=$ Interception threshold [mm month ${ }^{-1}$ ]

$P_{n}$ is separated over the unsaturated and saturated zone using a separation coefficient, $c_{r}[-]$. When the unsaturated zone reaches field capacity, $S_{u, \max }[\mathrm{mm}]$, the excess soil moisture (exceeding $S_{\text {excess }}$ ) is routed towards the saturated zone using a time scale $K_{u}=3$ months. Below $S_{\text {excess }}$, there is no exchange of storage between $S_{u}$ and $S_{s}$. Transpiration from the unsaturated zone is described by the following relation by Rijtema and Aboukhaled (1975):

$T_{a}=\min \left(\frac{1}{0.5 \cdot S_{u, \max }} \cdot T_{p} \cdot S_{u}, T_{p}\right)$

Where

$T_{a} \quad=$ Actual transpiration $\left[\mathrm{mm}\right.$ month $\left.^{-1}\right]$

$S_{u, \max } \quad=$ Field capacity $[\mathrm{mm}]$

$T_{p} \quad=$ Potential transpiration [mm]

$S_{u} \quad=$ Storage in unsaturated zone $[\mathrm{mm}]$

$S_{u, \text { max }}$ was defined according to a land use map. $S_{s, \max }$ was made dependent on the difference between elevation and the nearest higher order stream.

$S_{s, q}=S_{s, \max } \cdot q_{c}$

The saturated zone consists of a dead storage zone below 0 , from which capillary rise, $C$ is possible. This is described as follows:

$C=C_{\min } \quad S_{s} \leq S_{s, \min }$

or:

$C=C_{\max } \quad S_{s}>S_{s, \min }$

where $C_{\min }\left[\mathrm{mm} \mathrm{month}^{-1}\right]$ is the minimal capillary rise equal to $2 \mathrm{~mm} / \mathrm{month}$ and $C_{\max }\left[\mathrm{mm} \mathrm{month}^{-1}\right.$ ] is a calibration parameter, larger than $C_{\min }$. $S_{s, \min }$ was fixed at $-25 \mathrm{~mm}$ for the entire basin.

Furthermore the saturated zone consists of two linear reservoirs, which are separated by a threshold $S_{s, q}$ and bounded by $S_{s, \max }$. Slow and quick recession coefficients generate runoff from this reservoir. $S_{s, q}$ represents the threshold where the dambo drainage network becomes active. Overtop of the saturated zone represents rapid subsurface flow.

$q_{c}[-]$ is a calibration coefficient (the quick reacting component) between 0 and $1 . K_{s}$ and $K_{q}$ were determined to be 12 months and 4 months respectively from recession curve analysis. The remainder of the parameters was calibrated. The Muskingum parameters were not part of the model structure as such and were calibrated a posteriori. 

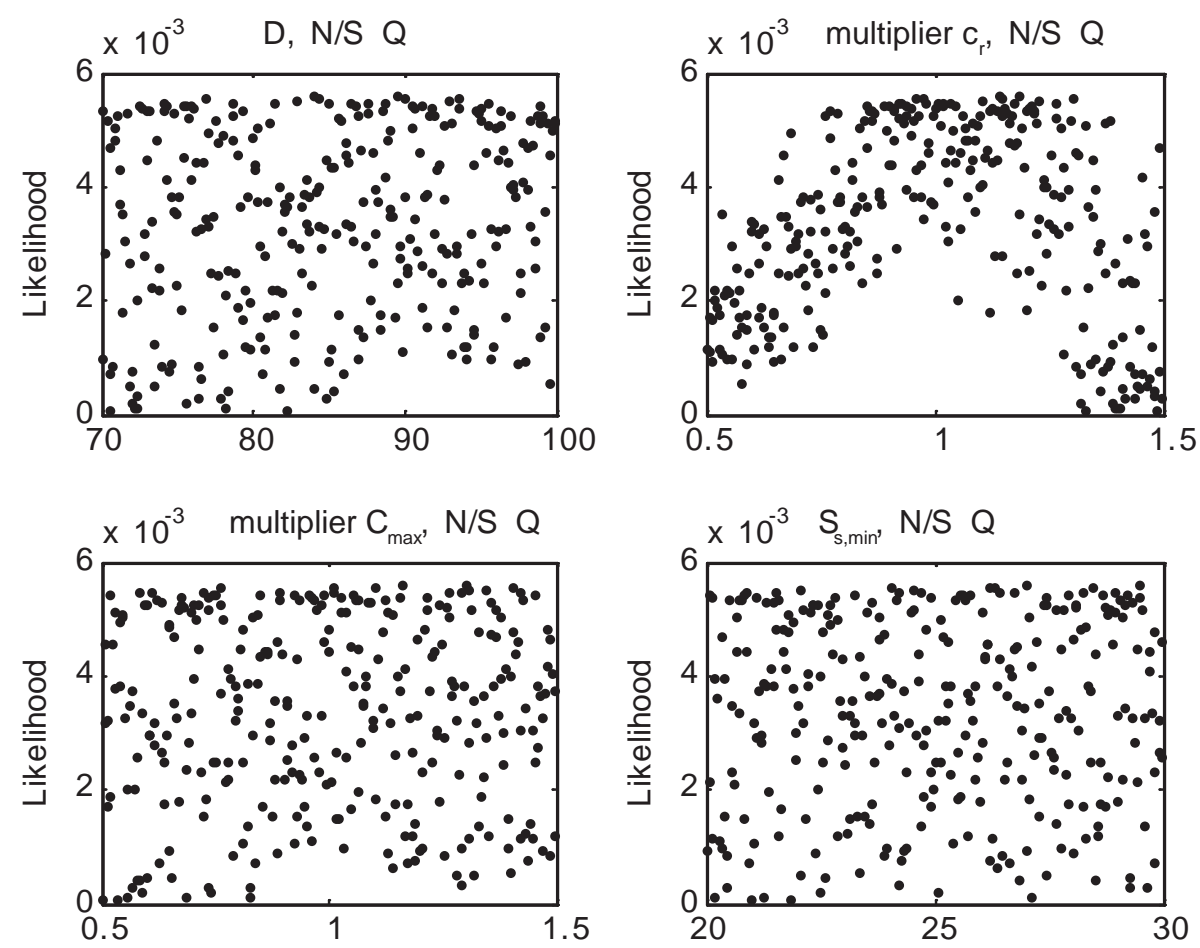

Fig. 7. GLUE likelihood dotty plots on Lukulu watershed using the STREAM model. $D$ [mm month $\left.{ }^{-1}\right]$ is the interception threshold, $c_{r}[-]$ separates effective rainfall in percolation and storage in the unsaturated zone, $C_{\max }\left[\mathrm{mm}\right.$ month $\left.^{-1}\right]$ is the maximum capillary rise and $S_{s, \text { min }}$ [mm] is the dead-storage level. $c_{r}$ and $C_{\max }$ were variable over the sub-basins and therefore multiplied by a constant for each run.

$D, c_{r}, C_{\max }$ and $S_{s, \min }$ were selected to be included in the GLUE uncertainty assessment, since the model performance was most sensitive to these parameters. Gauging time series at Lukulu were used to apply GLUE. A priori parameter sets were selected from a uniform distribution of the parameters within a pre-defined range. The Nash-Sutcliffe efficiency (Nash and Sutcliffe, 1970) was used as a performance measure. The GLUE dotty plots (Fig. 7) show a poor identifiability of all parameters except the multiplier for $c_{r}$. Table 1 shows how the different parameters were determined. A possible parameter set is given in Table 2.

\subsection{Lumped Elementary Watershed (LEW)}

LEW is a semi-distributed conceptual modelling approach. It has been designed specifically for modelling the Zambezi river and has been applied for the first time in this study. It is expected that the model concept can be applied on a wide range of river basins. The river basin is subdivided into smaller watersheds, which are modelled in a lumped manner. The outlets of individual watersheds are located at gauging points, confluence points with a higher order stream or at points where a transition between mildly sloping and shallow areas is observed in the DEM.

A model structure for the upper Zambezi has been developed by trial and error of different possible model structures.
Table 1. The method of determination of STREAM parameters.

\begin{tabular}{ll}
\hline Parameter & Determination method \\
\hline$S_{s, \max }$ & Relation with land use map \\
$q_{c}$ & Calibration \\
$K_{q}$ & Recession curve analysis \\
$K_{s}$ & Recession curve analysis \\
$D$ & GLUE \\
$c_{r}$ & GLUE \\
$C_{\max }$ & GLUE \\
$S_{s, \min }$ & GLUE \\
\hline
\end{tabular}

16 sub-catchments were delineated (see Fig. 8). The model structures had to serve 3 requirements:

- The amount of parameters should be limited, preferably parameters, which can be estimated using available data.

- The conceptual structure should clearly represent the natural behaviour of the river basin.

- Calibration parameters should be well identifiable. This means that behavioural models should converge to an optimum in the parameter space. 
Table 2. Possible STREAM parameter set from GLUE. These parameters were considered lumped per sub-catchment.

\begin{tabular}{lcccc}
\hline Sub-catchment & $D\left[\mathrm{~mm} \mathrm{month}^{-1}\right]$ & $c_{r}[-]$ & $C_{\max }\left[\mathrm{mm} \mathrm{month}{ }^{-1}\right]$ & $q_{c}[-]$ \\
\hline Upstream Lukulu & 75 & 0.17 & 2 & 0.7 \\
Luanginga \& Barotse & 60 & 0.24 & 10 & 0.3 \\
Cuando & 55 & 0.29 & 4 & 0.5 \\
Upstream Vic. Falls & 65 & 0.27 & 8 & 0.3 \\
\hline
\end{tabular}

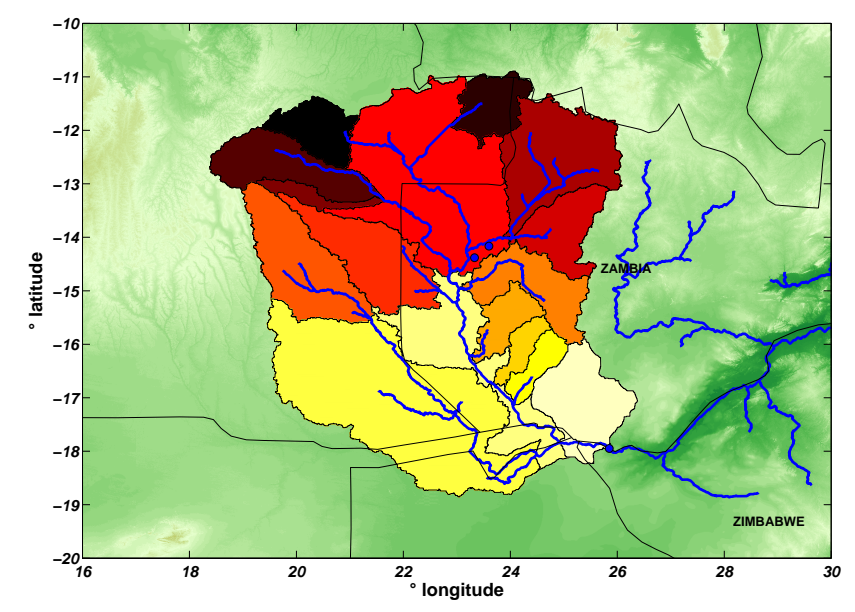

Fig. 8. The 16 delineated sub-catchments used in the LEW model.

It is in this approach acknowledged that the hydrology of the Zambezi river cannot be treated as uniform. Field observations (e.g. Bastiaansen, 1990) showed that the upper Zambezi main river segment is surrounded by enormous floodplains consisting of thick layers of Kalahari sands. Especially during the wet season, it is predominantly a wetland area. A logical assumption is therefore that water that is released through runoff in the relative steep uplands can easily spill and infiltrate again in the highly permeable soils of the downstream located flood plains: only a part of this runoff stays inside the river bed. The rest causes flooding of the wetlands and floodplains. This can very well be modelled in the LEW approach, since runoff generated in an upstream LEW can easily be laterally redistributed in a more downstream LEW. In STREAM, this physical phenomenon was merely taken into account in the calibration procedure by introducing the Muskingum river routing. Thus water that in reality resided in wetlands, has been modelled in STREAM as if it resided in the river.

Since the tributaries behave differently from the floodplain areas, the model structures have been tested on a tributary of the upper Zambezi, the Kabompo river, instead of the total area upstream of Lukulu. A small record of stream flow observations was available (1993-2001). Instead of precalibrating the model and determining parameter sensitivity afterwards using GLUE, the GLUE procedure was used to test

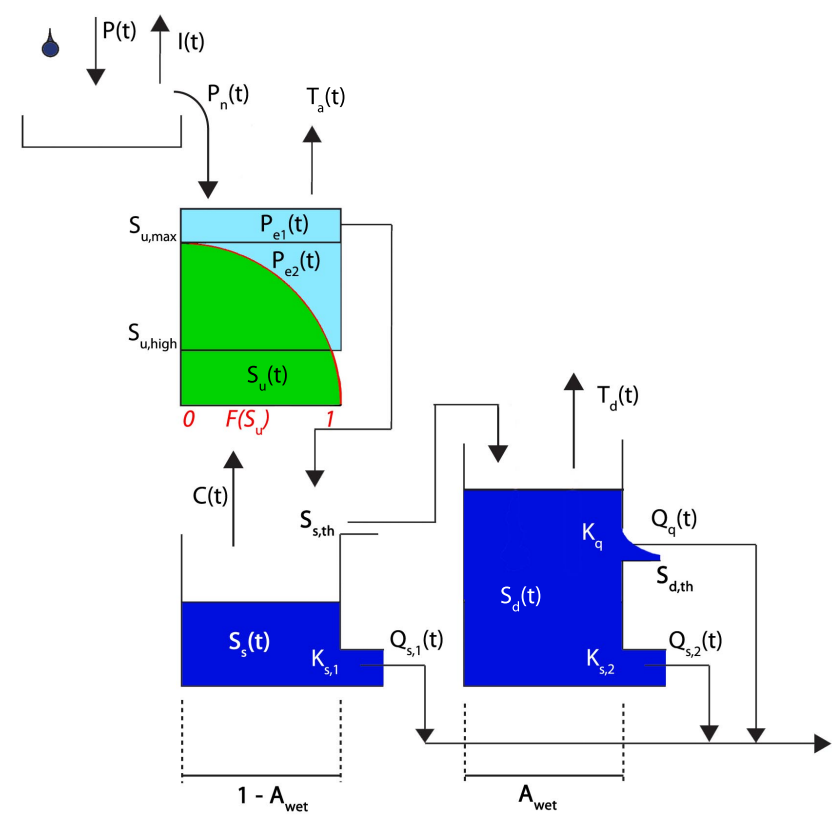

Fig. 9. LEW conceptual model structure.

several LEW model structures so as to give an indication of the confidence that a particular model structure offers. The LEW structure is very suitable for this approach since computational times are quite short due to the lumped character of the modelled watersheds.

Eventually, a model structure has been chosen that gave acceptable identifiability of parameters, subject to calibration. The Nash-Sutcliffe efficiency has been used on both absolute discharge numbers and the natural logarithm of the discharge numbers emphasising low flow. The structure consists of 2 zones (see Fig. 9): the first is a combination of two reservoirs representing the unsaturated $\left(S_{u}[\mathrm{~mm}]\right)$ and saturated zone $\left(S_{s}[\mathrm{~mm}]\right)$, while the second consists of one reservoir representing the wetland zone $\left(S_{d}[\mathrm{~mm}]\right)$, which accounts for the behaviour of dambos, marshes and floodplains. Both zones account for a part of the total watershed area, determined by a separation coefficient $A_{\text {wet }}$ [-], which can be estimated accurately using satellite imagery. The zones are interacting by an overtop of the saturated zone, which occurs when $S_{s}$ exceeds $S_{s, t h}[\mathrm{~mm}]$. The unsaturated zone is modelled similar to the HYMOD model (e.g. Vrugt et al., 2002): 
it is assumed that the spatial variability of soil moisture capacity $S_{u, \max }[\mathrm{mm}]$ can be described by a power function:

$$
\begin{gathered}
F\left(S_{u}\right)=1-\left(1-\frac{S_{u, \text { high }}}{S_{u, \max }}\right)^{B} \\
0 \leq S_{u, \text { high }} \leq S_{u, \max }
\end{gathered}
$$

where $F[-]$ represents the fraction of the LEW that has a soil moisture capacity lower than $S_{u}$ and $B[-]$ determines the spatial variability of the soil moisture capacity. $P_{e 1}$ and $P_{e 2}\left[\mathrm{~mm}\right.$ month $\left.^{-1}\right]$ are excess rainfall components that are partitioned according to the moisture state of the catchment. When a fraction of the basin $F$ is saturated, $P_{e 2}$ will only be generated over this fractional area. $P_{e 1}$ only occurs when $F=1$. Interception (fast evaporation) and transpiration are described according to Eqs. (2) and (3). Capillary rise is considered dependent on the amount of available soil moisture:

$C=\min \left(C_{p o t} \cdot \frac{S_{u, \max } / B-S_{u}}{S_{u, \max } / B}, S_{s}\right)$

When overtop of the saturated zone occurs, water flows into the wetland zone where it is subject to open water evaporation $T_{d}\left[\mathrm{~mm} \mathrm{month}^{-1}\right]$ and 2 runoff mechanisms for surface and groundwater drainage $\left(K_{s}\right.$ and $\left.K_{q}\right)$, behaving like linear reservoirs. $K_{q}$ [month] represents the drainage network between the wetlands. This network only generates flow when a threshold $S_{d, t h}[\mathrm{~mm}]$ is exceeded. River routing is simulated, simply by using estimated lag times.

A number of parameters can be estimated directly from the recession periods in the hydrographs. Visualization of the natural logarithm of discharge provides a good indication of $K_{s}, K_{q}$ and $S_{s, t h}$. The first two parameters express themselves in the "steepness" of the recession curve, the latter should be found at the inflection point. Some visual calibration was necessary to correct for second order effects like capillary rise and evaporation. $S_{u, \max }, B$ and $S_{d, t h}$ have been included in the GLUE analysis. Figure 10 shows the GLUE results. It is clear that the LEW parameters demonstrate much more structure than the STREAM parameters. Particularly $S_{u, \max }$ and $B$, responsible for the soil depth and its areal distribution appear significant. Also the application of GLUE on the logarithms of $Q$ demonstrates that the threshold level for the dambo drainage is significant to describe the low flows.

For routing, a threshold $Q_{\max }$ has been introduced, which separates river flow from overbank flow. Since $Q_{\max }$ occurs downstream of the model structure presented in Fig. 9, it is not part of the calibration procedure and the GLUE framework.

The parametrization derived for the Kabompo river has been used for every tributary of the Zambezi upstream of Lukulu. $Q_{\max }$ has been calibrated per watershed. It determines to a large extent the peak behaviour of the hydrograph in the Zambezi. Peaks are seriously attenuated when low values for $Q_{\max }$ are chosen. The floodplain bordering the Zambezi has been considered independently. The
Table 3. The method of determination of LEW parameters.

\begin{tabular}{ll}
\hline Parameter & Determination method \\
\hline$D$ & Estimated \\
$S_{S, t h}$ & Recession curve analysis \\
$K_{S}$ & Recession curve analysis \\
$K_{q}$ & Recession curve analysis \\
$S_{u, \max }$ & GLUE \\
$B$ & GLUE \\
$S_{d, t h}$ & GLUE \\
$A_{\text {wet }}$ & Satellite imagery \\
\hline
\end{tabular}

key parameter $A_{\text {wet }}$ is different for the lower floodplains and marshes since they have a larger wetland zone. Downstream of Lukulu, the same approach has been followed: most parameters were set at equal values for all watersheds except for $Q_{\max }$ and $A_{\text {wet }}$. Fixing parameters over large areas prevents over-parametrization. Table 3 shows an overview of the parameters and the methods used to derive their values. Table 4 shows the parameter set obtained.

\subsection{Comparison of model approaches}

It is clear that the LEW model merits more confidence than the STREAM model. Although STREAM is capable of handling spatially distributed data sources, the model structure is the same in every cell and even quite important parameters are considered lumped. Because of this, GLUE has been applied on a relatively large catchment (upstream of Lukulu) in STREAM compared to LEW (Kabompo watershed). The Kabompo is probably better identifiable as being a hydrotope than the total Lukulu watershed. This is partly caused by the fact that the Lukulu upstream area is considerably larger, but also because part of the upstream generated discharge infiltrates in downstream located floodplain. This diffuses the effect of runoff from smaller watersheds on the discharge at Lukulu. Therefore it can be concluded that in the upper Zambezi, GLUE gives a clearer response when applied to tributaries than to the Zambezi itself.

The impact of small computational effort on modelling efforts should also be underlined. The search for a confident model structure is much easier in the LEW model since many computations can be done in a small time span. Perhaps a better STREAM structure could also have been found using GLUE, if more time was used. However it would consume too much computational effort to be effective in the end.

Looking at the structural behaviour, the LEW model structure represents a more heterogeneous hydrology. Firstly it provides a distribution function for soil moisture capacity. Secondly, the effective surface of the watersheds consists of two zones (instead of one), which are interconnected and react quite differently. Finally, using the STREAM approach, runoff is immediately routed towards the watershed's outlet, 

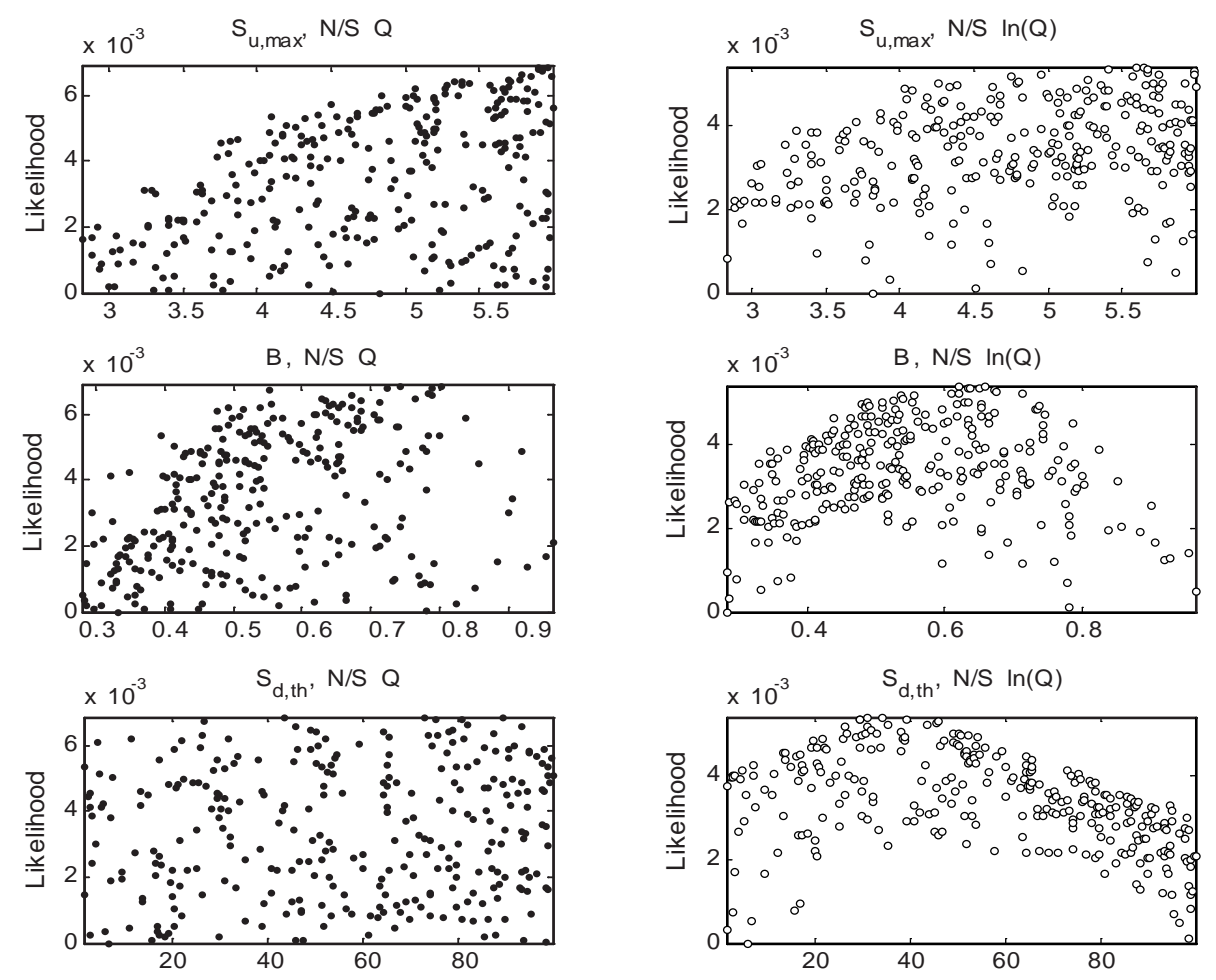

Fig. 10. GLUE likelihood dotty plots on Kabompo watershed. Filled dots: likelihoods for discharge. Open dots: likelihoods for the natural logarithmic of discharge. $S_{u, \max }[\mathrm{mm}]$ is the maximum field capacity, $B[-]$ is the power that describes the soil moisture capacity function and $S_{d, t h}[\mathrm{~mm}]$ is the drainage network threshold.

Table 4. LEW parameters. The values were adopted from gauged neighbouring catchments as much as possible.

\begin{tabular}{lccccccccc}
\hline Sub-catchment & $\begin{array}{c}D \\
{\left[\mathrm{~mm} \mathrm{month}{ }^{-1}\right]}\end{array}$ & $\begin{array}{c}S_{u, \text { max }} \\
{[\mathrm{mm}]}\end{array}$ & $\begin{array}{c}B \\
{[-]}\end{array}$ & $\begin{array}{c}C_{\text {pot }} \\
{\left[\mathrm{mm} \mathrm{month}{ }^{-1}\right]}\end{array}$ & $\begin{array}{c}S_{s, t h} \\
{[\mathrm{~mm}]}\end{array}$ & $\begin{array}{c}K_{S} \\
{[\mathrm{month}]}\end{array}$ & $\begin{array}{c}S_{d, t h} \\
{[\mathrm{~mm}]}\end{array}$ & $\begin{array}{c}K_{q} \\
{[\mathrm{month}]}\end{array}$ & $\begin{array}{c}A_{\text {wet }} \\
{[-]}\end{array}$ \\
\hline Uplands Lukulu & 50 & 1600 & 0.65 & 2 & 50 & 8 & 35 & 4 & 0.1 \\
Marsh upstr. Luk. & 50 & 1600 & 0.65 & 2 & 120 & 12 & 35 & 8 & 0.3 \\
Luanginga & 70 & 1000 & 0.8 & 2 & 100 & 3 & 35 & 3.5 & 0.1 \\
Upstr. Vic. Falls & 70 & 1000 & 0.8 & 2 & 100 & 3 & 35 & 1.2 & 0.1 \\
Barotse & 70 & 1000 & 0.8 & 2 & 100 & 3 & 35 & 1.2 & 0.7 \\
\hline
\end{tabular}

Table 5. Nash-Sutcliffe efficiencies for model results of STREAM and LEW for the calibration period 1960-1972.

\begin{tabular}{lcccc}
\hline \multirow{2}{*}{ Discharge gauge } & \multicolumn{2}{c}{ STREAM } & \multicolumn{2}{c}{ LEW } \\
& $Q$ & $\ln (Q)$ & $Q$ & $\ln (Q)$ \\
\hline Lukulu & 0.83 & 0.90 & 0.88 & 0.90 \\
Victoria Falls & 0.72 & 0.76 & 0.82 & 0.86 \\
\hline
\end{tabular}

while in reality it is stored in floodplain areas where it is subject to percolation and evaporation. This is considered to be a large shortcoming of the STREAM approach compared to LEW, especially in larger catchments with long residence times.

\section{Results}

Both models have been calibrated on discharges at Lukulu and Victoria Falls. They both show acceptable performance (see Figs. 11 and 12 and Table 5), illustrating equifinality not only within a certain model concept (that a wide range of parameters can yield acceptable results), but also between different model structures. In this case, however, it is not the simulated discharge that is of interest. Eventually the models are meant to do a comparative study with GRACE derived storage estimations. Therefore it is the internal storage of the model that should be behavioural. The internal states in STREAM are the unsaturated and saturated water content, $S_{u}$ and $S_{s}$. The LEW model has an additional dambo water content, $S_{d}$. Channel storage delays the runoff of water and 


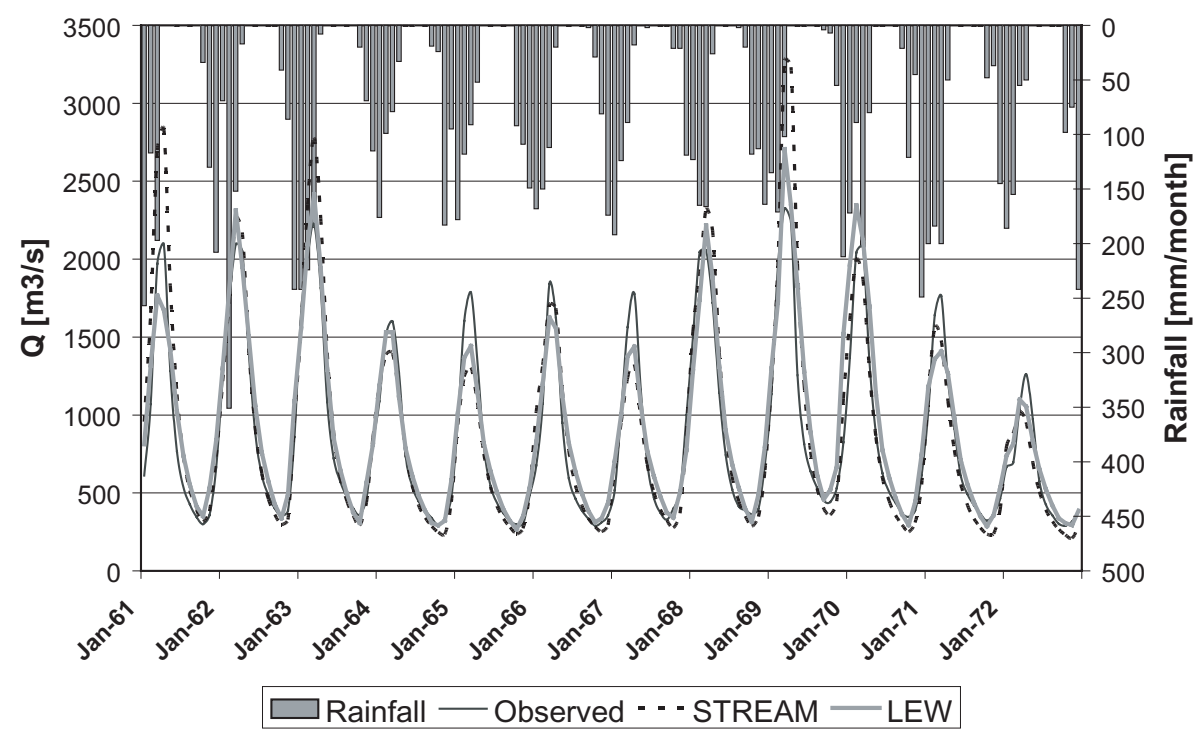

Fig. 11. Discharge time series at Lukulu from observations, STREAM and LEW results.

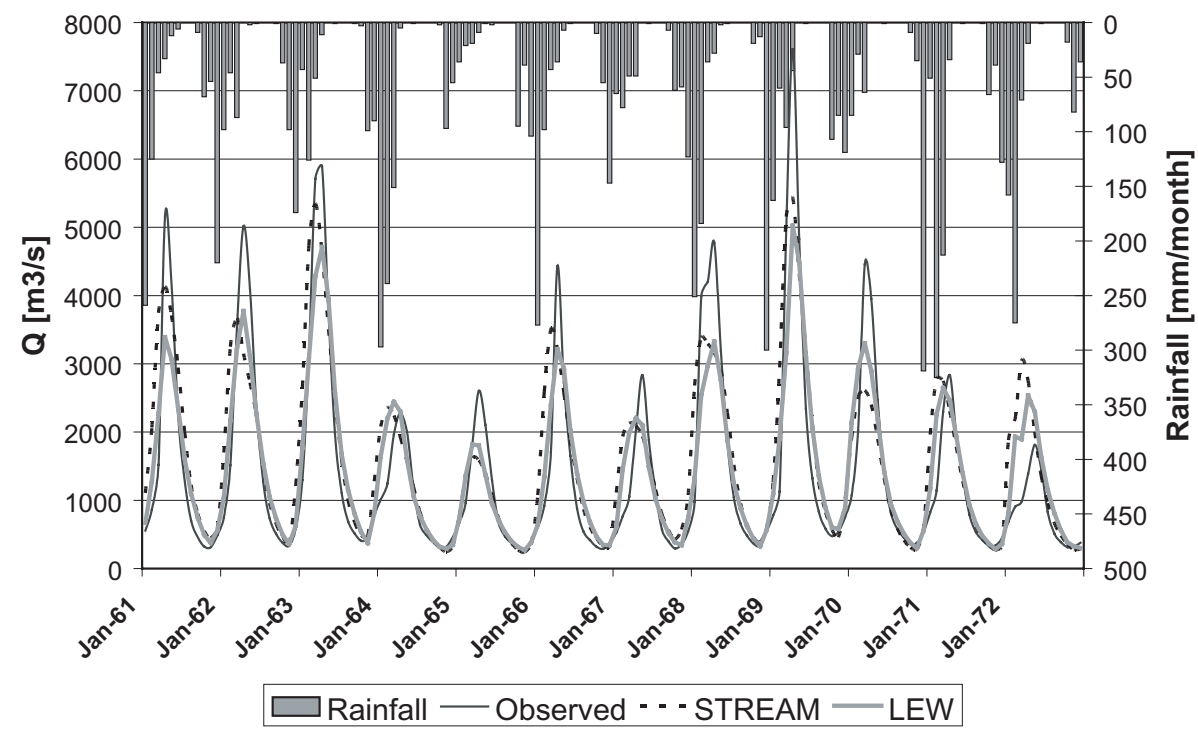

Fig. 12. Discharge time series at Victoria Falls from observations, STREAM and LEW results.

is therefore also a storage component. Channel storage in STREAM was calculated a posteriori by:

$\frac{\mathrm{d} S_{c h}}{\mathrm{~d} t}=Q_{\text {routed }}(t)-Q_{\text {unrouted }}(t)$

Thus total storage in STREAM is:

$\frac{\mathrm{d} S}{\mathrm{~d} t}=\frac{\mathrm{d}\left(S_{c h}+S_{u}+S_{S}\right)}{\mathrm{d} t}$
Total storage in LEW includes dambo storage, hence for LEW:

$\frac{\mathrm{d} S}{\mathrm{~d} t}=\frac{\mathrm{d}\left(S_{c h}+S_{u}+S_{s}+S_{d}\right)}{\mathrm{d} t}$

The resulting time series of storage change and total storage (Fig. 13) show a remarkable difference between the behaviour of STREAM and LEW. The total storage of LEW clearly shows a larger amplitude. In addition STREAM seems to have approximately the same storage level at the end of the dry season in every year, while LEW shows a larger interannual variation of the minimum storage. 

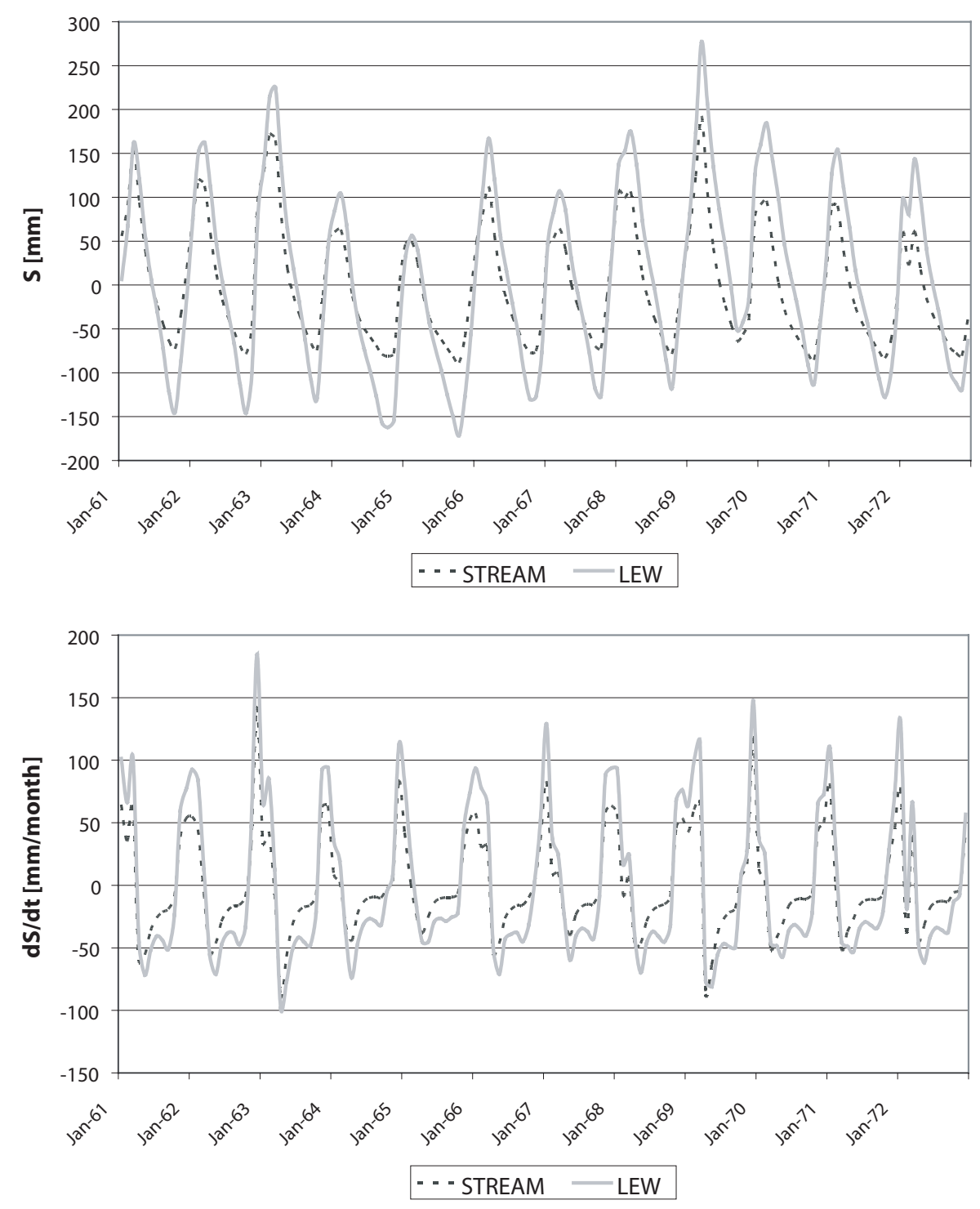

Fig. 13. Top: Estimated total storage. Bottom: Temporal change in total storage by STREAM and LEW.

Two reasons can be thought of for the cause of the larger storage fluctuations in LEW:

- More effective rainfall is entering the model

- Locally generated runoff infiltrates in downstream parts of the catchment, thus prolonging its residence time

It is likely that the bias is caused by a combination of these reasons. The interception threshold $D$, for example, is much larger in the STREAM model than in the LEW model. Therefore the amount of interception in the STREAM model is higher and less water is entering the storage zones. Presumably this is compensated for by directly routing the generated runoff through the channels. The LEW model on the other hand, allows for a larger input using a smaller $D$. More runoff is generated but instead of being evacuated directly, it is allowed to infiltrate in downstream floodplains, resulting in more transpiration and open water evaporation.

The larger interannual storage variation in LEW is not unrealistic. It is known that after a sequence of dry years it can take longer than expected before above average rainfall generates discharge at Victoria Falls. This is a result of threshold behaviour both in the saturated and the unsaturated zone due to deeply rooted vegetation that can access moisture below the discharge generating threshold. Hence a dead storage capacity is generated that has to be replenished before the runoff process can start. In the Lukulu catchment, $S_{u \text {, } \max }$ is as high as $1600 \mathrm{~mm}$.

The modelled groundwater storage component is relatively small. It does not mean that in reality the groundwater storage is minimal but merely that the model assumes that 
there is only a small amount of groundwater that contributes to the runoff. Therefore, it is rather the state of the unsaturated zone that determines the total storage behaviour during dry periods. However, it is likely that the system could also be conceptualized by introducing a part of the saturated zone that does not contribute to runoff, being too distant from the drainage network, but mainly interacts vertically with the unsaturated zone. This would imply that the unsaturated zone could be modelled much smaller. A clear illustration of equifinality. This is a point for further study and should also be investigated in the field by measurements of phreatic water levels in the surroundings of the Zambezi tributaries.

\section{Discussion}

The results of the GLUE analysis on both models not only relate to parameter uncertainty, but also to the confidence in total model structure. The fact that both models produce a reasonable discharge but nonetheless show a very different internal behaviour supports this. It proves that equifinality reaches further than only a wide choice in parameter spaces: should we not only produce an ensemble of model parameterizations, but also an ensemble of model structures? Naturally it is hard, if not impossible, to automate the process in which model structures are created at random by a computer and taken into account in a Monte Carlo analysis. It is a process that requires a certain amount of art and knowledge about the area to be modelled. GLUE however proved to be able to provide a measure for confidence in a model structure.

In view of the above statements, it is likely that there are more model structures that perform equally well as the STREAM and LEW structure. This underlines the need for orthogonal state observations that confirm or discard these model structures with more certainty. GRACE could offer these in the near future.

In the Zambezi basin, threshold behaviour is the main cause of non-linearity. Thresholds are present at almost all compartments of the rainfall-runoff system. Important thresholds identified are: the interception threshold $D$; the saturation level of the soil moisture $S_{u, \max }$; the groundwater threshold $S_{s, t h}$, where the dambo drainage system starts to develop; $S_{d, t h}$, where the drainage network starts flowing; and $Q_{\max }$, which is the discharge at which the floodplain becomes inundated. The reservoirs in the conceptual model are all linear, hence the non-linear behaviour is completely due to the threshold behaviour.

The threshold behaviour of both the STREAM and LEW model largely determines if peak behaviour in discharge occurs. In addition, we have observed that the runoff coefficient in the upper Zambezi is very low. It means that small errors in the rainfall time series can cause considerable under or overestimation of the internal states. Over longer periods, these error propagations accumulate and cause a large bias in model output. Although the performance on discharge is relatively well for both models, the results should be questioned regarding the sensitivity to rainfall errors. GRACE offers possibilities to reduce the effect of such input errors by updating the internal states with the observed value. It is expected that we can benefit most from GRACE when its storage solutions are separated into individual states. As discussed in Sect. 1, top layer soil moisture observations and lake altimetry data may prove useful for this. Eventually the essence lies in combining of remotely sensed data in order to benefit the most from each data source.

\section{Conclusions and recommendations}

Two hydrological models were used to describe the rainfall runoff relations in the upper Zambezi on a monthly time scale: a GIS-based model (STREAM) and a semi-distributed model (LEW). Without consideration of parameter sensitivity, both models show a reasonably good performance on discharge for the same calibration period. However, the behaviour of their storage reservoirs is quite different. Application of the GLUE framework showed a remarkable difference in parameter identifiability. A reliable LEW structure was obtained by applying GLUE on different conceptualisations, an approach that was possible since the computation time of LEW is short. The LEW model showed a far greater identifiability than the STREAM model. The fact that parameters are relatively well identifiable raises the confidence in the LEW model. Apparently it is better able to describe the actual hydrological processes in the river basin, since parameters are not able to compensate for each other's effect. This means that the orthogonality of these parameters is assured in the model structure, either because it was possible to determine some sensitive parameters a priori or because the parameters are responsible for the simulation of different unrelated responses. The analysis showed that GLUE does not only constrain parameterizations, but can also provide a modeller with a qualitative confidence in different tested model structures. A further constraint on parameters will become possible by including GRACE storage observations in the GLUE criteria.

It is recommended to study possibilities for state updating using GRACE as observational data to further constrain model uncertainties with respect to rainfall errors. Furthermore a separation of GRACE storage estimates by using lake altimetry and remotely sensed soil moisture observations is advised in order to benefit the most from GRACE.

Acknowledgements. This research is being funded by the Netherlands Organisation for Scientific Research (NWO). We are grateful for their support.

Edited by: A. Montanari 


\section{References}

Aerts, J. C. J. H., Kriek, M., and Schepel, M.: STREAM (Spatial Tools for River basins and Environment and Analysis of Management options): 'set up and requirements', Phys. Chem. Earth, 24(6), 591-595, 1999.

Bastiaansen, C. J. M.: Wetland types of Western Province and their suitability for rice cultivation, Land and Water Management Project, Tech. rep., Department of Agriculture, 1990.

Bastiaansen, C. J. M.: Lui River Valley Model and some of its applications, Tech. rep., Wageningen University and Research, 1995.

Bastiaanssen, W. M. G., Menenti, M., Feddes, R. A., and Holtslag, A. A. M.: The Surface Energy Balance Algorithm for Land (SEBAL). Part 1. Formulation, J. Hydrol., 212/213, 198-212, 1998.

Beven, K. J. and Binley, A. M.: The future of distributed models: model calibration and uncertainty prediction, Hydrol. Proc., 6, 279-298, 1992.

Beven, K. J. and Freer, J.: Equifinality, data assimilation, and uncertainty estimation in mechanistic modelling of complex environmental systems using the GLUE methodology, J. Hydrol., 249, 11-29, 2001.

Franks, S. W., Gineste, P., Beven, K. J., and Merot, P.: On constraining the predictions of a distributed model: The incorporation of fuzzy estimates of saturated areas into the calibration process, Water Resour. Res., 34, 787-797, 1998.

Gerrits, A. M. J.: Hydrological modelling of the Zambezi catchment from gravity measurements, Master's thesis, Delft, University of Technology, 2005.

Herman, A., Kumar, V. B., Arkin, P. A., and Kousky, J. V.: Objectively determined 10-day African rainfall estimates created for famine early warning systems, Int. J. Remote Sensing, 18, 10, 2147-2159, 1997.

Mohamed, Y. A., Bastiaanssen, W. G. M., and Savenije, H. H. G.: Spatial variability of evaporation and moisture storage in the swamps of the upper Nile studied by remote sensing techniques, J. Hydrol., 289, 145-164, 2004.
Mohamed, Y. A., van den Hurk, B. J. J. M., Savenije, H. H. G., and Bastiaanssen, W. G. M.: Hydroclimatology of the Nile: results from a regional climate model, Hydrol. Earth Syst. Sci., 9, 263278, 2005.

Nash, J. E. and Sutcliffe, J. V.: River flow forecasting through conceptual models, part 1: A discussion of principles, J. Hydrol., 10, 282-290, 1970.

New, M., Lister, D., Hulme, M., and Makin, I.: A high-resolution data set of surface climate over global land areas, Climate Res., 21, 1-25, 2002.

Rijtema, P. E. and Aboukhaled, A.: Crop water use, in: Research on crop water use, salt affected soils and drainage in the Arab Republic of Egypt, Tech. rep., FAO, Near East Regional Office, 5-61, 1975.

Savenije, H. H. G.: Determination of evaporation from a catchment water balance at a monthly time scale, Hydrol. Earth Syst. Sci., 1, 93-100, 1997.

Savenije, H. H. G.: Equifinality, a blessing in disguise?, Hydrol. Process., 15, 2835-2838, 2001.

Savenije, H. H. G.: The importance of interception and why we should delete the term evapotranspiration from our vocabulary, Hydrol. Process., 18, 1507-1511, 2004.

Scipal, K., Scheffler, C., and Wagner, W.: Soil moisture-runoff relation at the catchment scale as observed with coarse resolution microwave remote sensing, Hydrol. Earth Syst. Sci., 9, 173-183, 2005.

Sutcliffe, J. V. and Parks, Y. P.: The Hydrology of the Nile, IAHS Special Publication no. 5, IAHS Press, Institute of Hydrology, Wallingford, Oxfordshire OX10 8BB, UK, 1999.

Todd, M. C., Kidd, C., and Bellerby, T. J.: A combined satellite infrared and passive microwave technique for estimation of small scale rainfall, J. Atmos. Ocean Tech., 18(5), 742-755, 2001.

Vrugt, J. A., Bouten, W., Gupta, H. V., and Sorooshian, S.: Toward improved identifiability of hydrologic model parameters: The information content of experimental data, Water Resour. Res., 38(12), 1312, 2002. 